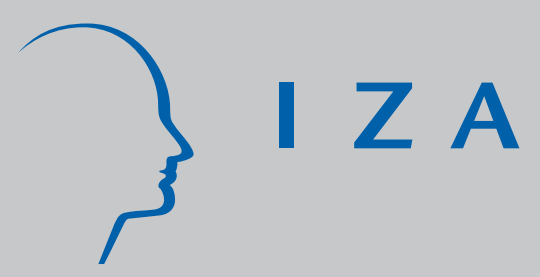

IZA DP No. 3150

The Elasticity of Labor Demand and the Minimum Wage

Leif Danziger

November 2007 


\title{
The Elasticity of Labor Demand and the Minimum Wage
}

\author{
Leif Danziger \\ Ben-Gurion University, \\ Central European University and IZA
}

Discussion Paper No. 3150

November 2007

\author{
IZA \\ P.O. Box 7240 \\ 53072 Bonn \\ Germany \\ Phone: +49-228-3894-0 \\ Fax: +49-228-3894-180 \\ E-mail: iza@iza.org
}

\begin{abstract}
Any opinions expressed here are those of the author(s) and not those of the institute. Research disseminated by IZA may include views on policy, but the institute itself takes no institutional policy positions.

The Institute for the Study of Labor (IZA) in Bonn is a local and virtual international research center and a place of communication between science, politics and business. IZA is an independent nonprofit company supported by Deutsche Post World Net. The center is associated with the University of Bonn and offers a stimulating research environment through its research networks, research support, and visitors and doctoral programs. IZA engages in (i) original and internationally competitive research in all fields of labor economics, (ii) development of policy concepts, and (iii) dissemination of research results and concepts to the interested public.
\end{abstract}

IZA Discussion Papers often represent preliminary work and are circulated to encourage discussion. Citation of such a paper should account for its provisional character. A revised version may be available directly from the author. 
IZA Discussion Paper No. 3150

November 2007

\section{ABSTRACT}

\section{The Elasticity of Labor Demand and the Minimum Wage}

We show that, contrary to widespread belief, low-pay workers do not generally prefer that the minimum wage rate be increased until the labor demand is unitary elastic. Rather, there exists a critical value of elasticity of labor demand so that increases in the minimum wage rate make low-pay workers better off for higher elasticities, but worse off for lower elasticities. This critical value decreases with unemployment benefits and increases with workers' risk aversion. We also show that in some countries the benefits for long-term unemployed are so low that workers would probably prefer that the minimum wage rate be decreased.

JEL Classification: J38

Keywords: elasticity of labor demand, minimum wage

Corresponding author:

Leif Danziger

Department of Economics

Ben Gurion University of the Negev

Beer-Sheva 84105

Israel

E-mail: danziger@bgu.ac.il 


\section{Introduction}

A common assumption in the minimum-wage literature is that low-wage workers as a group benefit from an increase in their total wage income. These workers would therefore be best off when the minimum wage rate is set at a level where the aggregate demand for low-wage labor is unitary elastic, and would be made better off by increases in the minimum wage rate as long as the aggregate demand for labor is inelastic. Accordingly, there is a close connection between the desirability of raising the minimum wage rate in order to improve the welfare of low-wage workers and the inelasticity of the demand for their labor. ${ }^{1}$ Indeed, the motivation for many empirical studies of the demand for low-wage labor is the desire to evaluate the efficacy of a legislated minimum wage rate for combatting poverty. ${ }^{2}$

In the face of a downward-sloping demand curve for labor, however, a minimum-wage legislation that raises workers' wages above the competitive level will inevitably lead to job losses for some of the workers. ${ }^{3} \quad$ The standard analysis implicitly assumes that the workers' income will then be reduced to zero and that their free time has no value, i.e., that workers' reservation wage rates are zero. In reality, however, workers are likely to collect unemployment benefits, and they may value leisure and engage in home production. Therefore, although they would be worse off than if they were employed at the minimum wage rate, they may not be as badly off as assumed. In other words, unemployed workers' reservation wage rates are likely to be positive.

The standard analysis also implicitly assumes that workers care only about their expected wage income (the income at the minimum wage rate multiplied by the employment probability) and thus are risk neutral. More realistically, however, workers are likely to be

\footnotetext{
${ }^{1}$ For example, according to Sobel (1999 p. 761) one of "the most popularly stated goals of minimumwage policy [is to choose] the minimum-wage rate at which the relevant labor demand is unitary elastic maximizing the total earnings of minimum-wage workers." See also Freeman (1995), Deere et al. (1996), and Addison and Blackburn (1999).

${ }^{2}$ See Neumark and Wascher (1992), Deere et al. (1995), and Burkhauser et al. (2000).

3 Card and Krueger (1995) question whether it is empirically true that a binding minimum wage rate always reduces employment. They suggest that low-pay firms may behave monopsonistically, in which case the minimum wage rate may have a positive effect on employment (Stigler, 1946). For ensuing discussions, see Neumark and Wascher (1994, 2000), Dickens et al. (1999), and Card and Krueger (2000).
} 
risk averse and hence be negatively affected by the uncertainty associated with whether they will earn the minimum wage rate or will have to make do with their reservation wage rates.

The purpose of this paper is to provide a more satisfactory framework for analyzing how a minimum wage rate affects workers' welfare. In particular, we construct a model that can be used to examine how unemployment benefits and risk aversion affect the range of labor demand elasticities for which increases in the minimum wage rate benefit the working poor. We first show that for each minimum wage rate there exists a critical value of the elasticity of labor demand - which is generally different from minus unity - such that an increase in the minimum wage rate makes workers better off if labor demand is less elastic than the critical value, but worse off if labor demand is more elastic than the critical value. We then prove that the critical value of the elasticity of labor demand decreases with unemployment benefits and increases with workers' risk aversion.

For clarity of exposition, we first derive and discuss our results in a static model where workers' reservation wage rates are independent of the duration of unemployment. We next extend our results to the more realistic case where workers' reservation wage rates depend on the duration of unemployment.

We also inquire how workers would be affected by an increase in the minimum wage rate for reasonable values of unemployment benefits and risk aversion. It is shown that workers would gain from an increase in the minimum wage rate at average OECD benefit levels for short-term unemployment. Workers would also gain from an increase in the minimum wage rate at average OECD benefit levels for long-term unemployment, unless they are very risk averse. However, there are some OECD countries in which the unemployment benefits are so low in the later phase of unemployment that, taking the risk of long-term unemployment into account, it is likely that workers would be harmed by increases in the minimum wage rate.

\section{The Model}

We consider a low-wage labor market that is competitive except for a legislated minimum wage rate, which is denoted by $m$. Each worker is endowed with one unit of indivisible 
time, and the utility of a worker who is employed at the minimum wage rate is $U(m)$, where $U^{\prime}>0$ and $U^{\prime \prime} \leq 0$. A worker who does not get employed at the minimum wage rate obtains the utility $U(b+a)$ of the reservation wage rate $b+a$, where $b \geq 0$ is the unemployment benefit and $a$ is the value of the unemployed worker's leisure and home production. Workers have different $a$ 's and we assume that these are distributed with unitary density on $[\underline{a}, \bar{a}]$, where $\underline{a}<\bar{a}$. It follows that the lowest reservation wage rate is $b+\underline{a}$, and that the supply of minimum-wage workers is given by $N(m) \equiv \int_{\underline{a}}^{m-b} d a=m-b-\underline{a}$ for $m \in[b+\underline{a}, b+\bar{a}]$.

The labor demand at the minimum wage rate is given by $L(m)$, where $L^{\prime}(m)<0$. The minimum wage rate is set above the market-clearing level, but not so high as to eliminate all employment; that is, $0<L(m)<N(m)$. Consequently, some but not all of the $N(m)$ workers succeed in finding employment at the minimum wage rate, while the remaining $N(m)-L(m)$ workers are involuntarily unemployed. Each of the $N(m)$ workers has the same probability of finding employment. Therefore, the workers' welfare is given by

$$
\begin{aligned}
W(m) & \equiv U(m) L(m)+A(m)[N(m)-L(m)]+\int_{m-b}^{\bar{a}} U(b+a) d a \\
& =[U(m)-A(m)] L(m)+\int_{\underline{a}}^{\bar{a}} U(b+a) d a,
\end{aligned}
$$

where

$$
A(m) \equiv \frac{\int_{\underline{a}}^{m-b} U(b+a) d a}{N(m)}
$$

is the average utility of involuntarily unemployed workers when the minimum wage rate is $m .^{4}$

Differentiating $W(m)$ with respect to $m$, we obtain that the effect of an increase in the minimum wage rate on the workers' welfare is

$$
\begin{aligned}
\frac{d W(m)}{d m} & =\left[U^{\prime}(m)-A^{\prime}(m)\right] L(m)+[U(m)-A(m)] L^{\prime}(m) \\
& =\left(e_{U}+e_{L}\right) \frac{[U(m)-A(m)] L(m)}{m}
\end{aligned}
$$

\footnotetext{
${ }^{4}$ Depending on the utility function, we may require that $b+\underline{a}$ is bounded below in order for $A(m)$ and hence $W(m)$ to be bounded below. The model assumes that all unemployed workers are eligible to receive unemployment benefits.
} 
where $e_{U} \equiv m\left[U^{\prime}(m)-A^{\prime}(m)\right] /[U(m)-A(m)]$ is the elasticity of the marginal gain of utility from employment at the minimum wage rate with respect to $m$, and $e_{L} \equiv m L^{\prime}(m) / L(m)$ is the (negative) elasticity of the labor demand with respect to $m$. Thus, according to expression (1), the effect of an increase in the minimum wage rate on the workers' welfare has the same sign as the sum of these two elasticities, i.e., as $e_{U}+e_{L}$. We assume that $e_{U}>0$, since the workers' welfare would otherwise decrease with the minimum wage rate even if the demand for labor were completely inelastic.

For every value of $e_{U}$, there exists a unique critical value of $e_{L}$ which is denoted by $e_{L}^{*}$ and defined by $e_{L}^{*} \equiv-e_{U}$. Hence, $e_{L}^{*}<0$ and it follows that the workers' welfare is maximized if $e_{L}=e_{L}^{*}{ }^{5}$ Furthermore, the workers' welfare increases with the minimum wage rate if $e_{L}>e_{L}^{*}$, but decreases if $e_{L}<e_{L}^{*}$.

In the next sections we establish how $e_{L}^{*}$ depends on the unemployment benefit and on the workers' risk aversion.

\section{The Unemployment Benefit}

First, observe that since $A^{\prime}(m)=[U(m)-A(m)] / N(m)$, we may write $e_{U}$ as

$$
e_{U}=\frac{m U^{\prime}(m)}{U(m)-A(m)}-\frac{m}{N(m)}
$$

and hence $e_{L}^{*}$ as

$$
e_{L}^{*}=-\frac{m U^{\prime}(m)}{U(m)-A(m)}+\frac{m}{N(m)} .
$$

To determine the effect of the unemployment benefit on the critical value of $e_{L}$, we

${ }^{5}$ It is assumed that $e_{L}=e_{L}^{*}$ indicates a maximum. Differentiating expression (1) with respect to $m$ shows that the second-order condition for a maximum is

$$
\frac{U^{\prime \prime}(m)-A^{\prime \prime}(m)}{U^{\prime}(m)-A^{\prime}(m)}+\frac{2 L^{\prime}(m)}{L(m)}-\frac{m L^{\prime \prime}(m)}{e_{L}^{*} L(m)}<0 .
$$


differentiate $e_{L}^{*}$ with respect to $b$, which yields ${ }^{6}$

$$
\begin{aligned}
\frac{d e_{L}^{*}}{d b} & =-\frac{m U^{\prime}(m)\left[-U(b+\underline{a}) N(m)+\int_{\underline{a}}^{m-b} U(b+a) d a\right]}{[U(m)-A(m)]^{2}[N(m)]^{2}}+\frac{m}{[N(m)]^{2}} \\
& =-\frac{m U^{\prime}(m)[A(m)-U(b+\underline{a})]}{[U(m)-A(m)]^{2} N(m)}+\frac{m}{[N(m)]^{2}} .
\end{aligned}
$$

This becomes, by substitution of $e_{L}^{*}-m / N(m)$ instead of $-m U^{\prime}(m) /[U(m)-A(m)]$,

$$
\frac{d e_{L}^{*}}{d b}=\frac{[A(m)-U(b+\underline{a})] e_{L}^{*}}{[U(m)-A(m)] N(m)}+\frac{m[U(m)+U(b+\underline{a})-2 A(m)]}{[U(m)-A(m)][N(m)]^{2}} .
$$

The first term in expression (3) is negative since $e_{L}^{*}<0$ and the average utility of involuntarily unemployed workers exceeds the utility of the involuntarily unemployed worker with the lowest reservation wage rate so that $A(m)-U(b+\underline{a})>0$. The second term in expression (3) is non-positive since the weak concavity of the workers' utility function (i.e., $U^{\prime \prime} \leq 0$ ) entails that the average utility of involuntarily unemployed workers is at least equal to the average of the utilities of the unemployed workers with the highest and the lowest reservation wage rates, and hence, that $U(m)+U(b+\underline{a})-2 A(m) \leq 0$. Thus, expression (3) is negative, implying that the unemployment benefit affects $e_{U}$ positively and therefore the critical value of $e_{L}$ negatively. The reason for this is that a higher utility of unemployed workers reduces the gain from employment at the minimum wage rate, which makes the workers more willing to accept the adverse employment consequences of a higher minimum wage rate. Hence, the higher the unemployment benefit, and therefore the higher the utility of unemployed workers, the lower are the values of $e_{L}$ for which the workers would still gain from an increase in the minimum wage rate. That is, $e_{L}^{*}$ decreases with the unemployment benefit. ${ }^{7}$

${ }^{6}$ We use that

$$
\frac{d A(m)}{d b}=\frac{-U(b+\underline{a}) N(m)+\int_{\underline{a}}^{m-b} U(b+a) d a}{[N(m)]^{2}}
$$

7 For a similar reason, $e_{L}^{*}$ also decreases with $\underline{a}$. In fact, $d e_{L}^{*} / d \underline{a}=d e_{L}^{*} / d b$. On the other hand, a uniform change in the density of workers at all levels of $a$ does not affect the average utility of involuntarily unemployed workers and hence has no effect on $e_{L}^{*}$. 


\section{Risk Aversion}

Workers with utility function $V$ are more risk averse than workers with utility function $U$ if there exists an increasing strictly concave transformation $f: U \rightarrow V$ such that $V(b+a)=$ $f[U(b+a)]$ for all $b+a$. Let the average utility of involuntarily unemployed workers with utility function $V$ be denoted by

$$
A_{V}(m) \equiv \frac{\int_{\underline{a}}^{m-b} V(b+a) d a}{N(m)} .
$$

Therefore, the elasticity of the marginal gain of utility from employment at the minimum wage rate with respect to $m$ is

$$
\frac{m V^{\prime}(m)}{V(m)-A_{V}(m)}-\frac{m A_{V}^{\prime}(m)}{V(m)-A_{V}(m)} .
$$

Since $A_{V}^{\prime}(m)=\left[V(m)-A_{V}(m)\right] / N(m)$, this expression equals

$$
\begin{aligned}
& \frac{m V^{\prime}(m)}{V(m)-A_{V}(m)}-\frac{m}{N(m)} \\
= & \frac{m f^{\prime}[U(m)] U^{\prime}(m)}{f[U(m)]-\left\{\int_{\underline{a}}^{m-b} f[U(b+a)] d a\right\} / N(m)}-\frac{m}{N(m)} .
\end{aligned}
$$

The strict concavity of $f$ implies that

$$
f^{\prime}[U(m)]<\frac{f[U(m)]-\left\{\int_{\underline{a}}^{m-b} f[U(b+a)] d a\right\} / N(m)}{U(m)-\int_{\underline{a}}^{m-b} U(b+a) d a / N(m)},
$$

and hence that (4) is strictly less than

$$
\begin{aligned}
& \frac{m U^{\prime}(m)}{U(m)-\int_{\underline{a}}^{m-b} U(b+a) d a / N(m)}-\frac{m}{N(m)} \\
= & \frac{m U^{\prime}(m)}{U(m)-A(m)}-\frac{m}{N(m)} .
\end{aligned}
$$

Thus, the elasticity of the marginal gain of utility from employment at the minimum wage rate with respect to $m$ is less with utility function $V$ than with utility function $U$, and $e_{L}^{*}$ 
therefore increases with the workers' risk aversion. The logic is that increased risk aversion decreases the marginal gain of utility from employment at the minimum wage rate relative to the average gain of utility, which affects the elasticity of the marginal gain of utility from employment negatively. This reflects that the more risk averse the workers are, the more concerned they will be about the risk of not being able to find employment at the minimum wage rate, and therefore the more reluctant they will be to bear the negative employment consequences of a higher minimum wage rate. Consequently, the larger must $e_{L}$ be for workers to be made better off by an increase in the minimum wage rate, so that the critical value of $e_{L}$ increases with the workers' risk aversion.

\section{Some Consequences}

In the special case that the lowest reservation wage rate is zero $(b+\underline{a}=0)$ and workers are risk neutral $\left(U^{\prime \prime}=0\right)$, then $e_{U}=1$. Accordingly, the critical value of $e_{L}$ that maximizes the workers' welfare is minus unity for all $m$, since the average gain in a worker's expected utility due to the minimum wage rate is then proportional to $m$. The total gain in the workers' expected utility is then proportional to $m L(m)$, which is maximized at a minimum wage rate for which the demand for labor is unitary elastic $\left(e_{L}=-1\right)$, as presumed in much of the literature. Furthermore, workers benefit from an increase in the minimum wage rate as long as the demand for labor is inelastic $\left(e_{L}>-1\right)$, but are harmed by an increase in the minimum wage rate if the demand for labor is elastic $\left(e_{L}<-1\right)$.

More generally, the lowest reservation wage rate may differ from zero and/or the workers may be risk averse. It is then likely that $e_{U} \neq 1$, and, hence, that the critical value of $e_{L}$ will differ from minus unity. For instance, since $e_{L}^{*}$ decreases with the unemployment benefit, it follows that if the lowest reservation wage rate is positive and workers are risk neutral, then $e_{L}^{*}<-1$ (more precisely, $e_{L}^{*}=-m / N(m)$ ). In other words, if $b+\underline{a}>0$, then the expected utility of risk-neutral workers not only increases with the minimum wage rate if the demand for labor is inelastic, but it also increases with the minimum wage rate if the demand for labor is unitary elastic and if it is elastic as long as the elasticity exceeds $e_{L}^{*}=-m / N(m)$. In a similar vein, since $e_{L}^{*}$ increases with the workers' risk aversion, it follows that if the 
lowest reservation wage rate is zero and workers are risk averse, then $e_{L}^{*}>-1$. That is, if $b+\underline{a}=0$, then risk-averse workers gain from an increase in the minimum wage rate only if the labor demand is sufficiently inelastic.

\section{Short- and Long-Term Unemployment}

In reality, the unemployment benefit is typically less generous for the long-term unemployed than for the short-term unemployed. In addition, the value of an unemployed worker's leisure and home production may vary with the length of unemployment, for example, due to a positive habituation effect or a negative externality of the unemployed worker on the rest of the family. As a consequence, an unemployed worker's utility is likely to depend on how long a time he has been unemployed. ${ }^{8} \quad$ A worker's reservation wage rate may then depend on his employment history as well as on his expectations about the future. In order to increase realism and capture some of the dynamic ramifications of the minimum wage rate, in this section we extend the static model by embedding the minimum wage rate in an overlapping-generations framework.

Suppose that a new generation consisting of a unit continuum of minimum-wage workers is born in each period and that workers live for two periods. If a worker is employed at the minimum wage rate in a period, then his utility in that period is $U(m)$. If a worker is unemployed in the first period of his life, his utility in that period is $U\left(b_{1}+a_{1}\right)$, where $b_{1}>0$ is the unemployment benefit for a short-term unemployed and $a_{1}$ is the value of a short-term unemployed worker's leisure and home production. If a worker is unemployed in the second period of his life, then his utility depends on his employment status in the first period of his life. If he was employed in the first period of his life, his utility in the second period of his life is $U\left(b_{1}+a_{1}\right)$. If he was unemployed in the first period of his life, his utility in the second period of his life is $U\left(b_{2}+a_{2}\right)$, where $b_{2}, 0 \leq b_{2}<b_{1}$, is the unemployment benefit for a long-term unemployed and $a_{2}<a_{1}+b_{1}-b_{2}$ is the value of a long-term unemployed worker's leisure and home production. To simplify, we assume that all workers have the same $a_{1}$ and

\footnotetext{
8 See Clark et al. (2001). An employed worker's utility may also depend on whether he has been unemployed previously.
} 
$a_{2}$.

As in the static model where a worker's employment status in one period has no bearing on his reservation wage rate in another, it is assumed that the minimum wage rate is set such that the labor demand is positive but less than the labor supply. It is also assumed that each worker seeking employment has the same probability of being successful.

Since $b_{2}+a_{2}<b_{1}+a_{1}$, there are two distinct cases of interest: that in which $b_{1}+a_{1} \leq m$, and that in which $b_{2}+a_{2} \leq m<b_{1}+a_{1}$, and these will be examined separately in the following. ${ }^{9}$

\subsection{The Case of $b_{1}+a_{1} \leq m$}

If $b_{1}+a_{1} \leq m$, then all workers hope to find employment in both periods of their life. ${ }^{10}$ The total supply of minimum-wage labor in each period from the relevant two generations of workers is 2 , so that $\frac{1}{2} L(m)$ of the workers in each generation find employment. The workers' utility in the first period of their life is

$$
\frac{1}{2} U(m) L(m)+U\left(b_{1}+a_{1}\right)\left[1-\frac{1}{2} L(m)\right]
$$

and in the second period it is

$$
\frac{1}{2} U(m) L(m)+\frac{1}{2} U\left(b_{1}+a_{1}\right) L(m)\left[1-\frac{1}{2} L(m)\right]+U\left(b_{2}+a_{2}\right)\left[1-\frac{1}{2} L(m)\right]^{2} .
$$

The workers' welfare, which is given by the utility of the two generations of workers alive at the same time, is

$$
\begin{aligned}
& \frac{1}{2} U(m) L(m)+U\left(b_{1}+a_{1}\right)\left[1-\frac{1}{2} L(m)\right] \\
& +\frac{1}{2} U(m) L(m)+\frac{1}{2} U\left(b_{1}+a_{1}\right) L(m)\left[1-\frac{1}{2} L(m)\right]+U\left(b_{2}+a_{2}\right)\left[1-\frac{1}{2} L(m)\right]^{2} \\
= & U(m) L(m)-\frac{1}{4} U\left(b_{1}+a_{1}\right)[L(m)]^{2}-U\left(b_{2}+a_{2}\right) L(m)\left[1-\frac{1}{4} L(m)\right] \\
& +U\left(b_{1}+a_{1}\right)+U\left(b_{2}+a_{2}\right) .
\end{aligned}
$$

\footnotetext{
${ }^{9}$ If $m<b_{2}+a_{2}$, then workers will never seek employment.

${ }^{10}$ If $b_{1}+a_{1}=m$, it is assumed that all workers who are indifferent between working and not working choose to work.
} 
To determine the effect of an increase in the minimum wage rate on the workers' welfare, we differentiate this expression with respect to $m$, which yields

$$
U^{\prime}(m) L(m)+\left\{U(m)-\frac{1}{2} U\left(b_{1}+a_{1}\right) L(m)-U\left(b_{2}+a_{2}\right)\left[1-\frac{1}{2} L(m)\right]\right\} L^{\prime}(m) .
$$

This has the same sign as

$$
\frac{m U^{\prime}(m)}{U(m)-\frac{1}{2} U\left(b_{1}+a_{1}\right) L(m)-U\left(b_{2}+a_{2}\right)\left[1-\frac{1}{2} L(m)\right]}+e_{L} .
$$

Thus, the unique critical value of $e_{L}$ for which the workers' welfare is maximized is now given by ${ }^{11}$

$$
e_{L}^{*}=-\frac{m U^{\prime}(m)}{U(m)-\frac{1}{2} U\left(b_{1}+a_{1}\right) L(m)-U\left(b_{2}+a_{2}\right)\left[1-\frac{1}{2} L(m)\right]},
$$

and, as in the static model, the workers' welfare increases with the minimum wage rate if $e_{L}>e_{L}^{*}$, but decreases if $e_{L}<e_{L}^{*}$. Since an increase in employment decreases the likelihood that a worker who is unemployed in the first period of his life will also be unemployed in the second period of his life, it increases the average utility of involuntarily unemployed workers. Accordingly, the marginal gain of utility from employment at the minimum wage rate with respect to $m$ (the denominator of $e_{L}^{*}$ ) is no longer independent of the level of employment. In the present case, therefore, $e_{L}^{*}$ equals minus the partial elasticity of the marginal gain of utility from employment at the minimum wage rate with respect to $m$.

Expression (5) for the critical value of $e_{L}$ shows that $e_{L}^{*}$ is negatively related to $b_{1}$ and $b_{2}$, i.e., to both the short- and the long-run unemployment benefit. The effect on $e_{L}^{*}$ of the workers' risk aversion can be found by observing that if the workers would have the more risk-averse utility function $V$ instead of $U$ (i.e., $V$ is an increasing strictly concave transformation of $U$ ), then the critical value of $e_{L}$ would be given by

$$
-\frac{m V^{\prime}(m)}{V(m)-\frac{1}{2} V\left(b_{1}+a_{1}\right) L(m)-V\left(b_{2}+a_{2}\right)\left[1-\frac{1}{2} L(m)\right]}
$$

11 Assuming that the second-order condition for a maximum

$$
\frac{U^{\prime \prime}(m)}{U^{\prime}(m)}+\frac{2 L^{\prime}(m)}{L(m)}-\frac{m L^{\prime \prime}(m)}{e_{L}^{*} L(m)}<0
$$

is satisfied. 
instead of (5). Since $V$ being strictly more concave than $U$ implies that

$$
\begin{aligned}
& -\frac{m V^{\prime}(m)}{V(m)-\frac{1}{2} V\left(b_{1}+a_{1}\right) L(m)-V\left(b_{2}+a_{2}\right)\left[1-\frac{1}{2} L(m)\right]} \\
> & -\frac{m U^{\prime}(m)}{U(m)-\frac{1}{2} U\left(b_{1}+a_{1}\right) L(m)-U\left(b_{2}+a_{2}\right)\left[1-\frac{1}{2} L(m)\right]},
\end{aligned}
$$

it follows that $e_{L}^{*}$ is positively related to the workers' risk aversion. Thus, it can be concluded that if the unemployment benefit depends on the length of unemployment and $b_{1}+a_{1} \leq$ $m$, then the results for the effects on the critical value of $e_{L}$ of the short- and long-run unemployment benefit and the workers' risk aversion are analogous to those obtained in the static model. ${ }^{12}$

\subsection{The Case of $b_{2}+a_{2} \leq m<b_{1}+a_{1}$}

If $b_{2}+a_{2} \leq m<b_{1}+a_{1}$, then all workers hope to find employment in the first period of their life, but want to work in the second period of their life only if they were not successful at finding employment in the first period. ${ }^{13}$ Accordingly, the supply of these workers is unity in the first period of their life and $1-p$ in the second period, where $p$ denotes the probability that a worker who wants to work can find employment. In each period, the total supply of minimum-wage labor from the relevant two generations of workers is $2-p$, so that the probability of finding employment is determined by $p=L(m) /(2-p) \Rightarrow p=1-[1-L(m)]^{1 / 2}$. The workers' utility in the first period of their life is

$$
U(m) p+U\left(b_{1}+a_{1}\right)(1-p)
$$

and in the second period it is

$$
U(m)(1-p) p+U\left(b_{1}+a_{1}\right) p+U\left(b_{2}+a_{2}\right)(1-p)^{2} .
$$

\footnotetext{
12 Furthermore, $d e_{L}^{*} / d a_{1}=d e_{L}^{*} / d b_{1}$ and $d e_{L}^{*} / d a_{2}=d e_{L}^{*} / d b$, and $e_{L}^{*}$ is independent of the size of each generation of workers. If $b_{2}+a_{2}=0$ and workers are risk neutral, then $e_{L}^{*}<-1$ and an increase in $m$ benefits the workers not only if the demand for labor is inelastic or unitary elastic, but also if the demand for labor is elastic as long as it is not too elastic.

${ }^{13}$ If $b_{2}+a_{2}=m$, it is assumed that all workers who are indifferent between working and not working choose to work.
} 
Accordingly, the workers' welfare as given by the utility of the two generations of workers alive at each period is

$$
\begin{aligned}
& U(m) p+U\left(b_{1}+a_{1}\right)(1-p)+U(m)(1-p) p+U\left(b_{1}+a_{1}\right) p+U\left(b_{2}+a_{2}\right)(1-p)^{2} \\
= & {\left[U(m)-U\left(b_{2}+a_{2}\right)\right] p(2-p)+U\left(b_{1}+a_{1}\right)+U\left(b_{2}+a_{2}\right) . }
\end{aligned}
$$

The effect of an increase in the minimum wage rate on the workers' welfare is found by differentiating this expression with respect to $m$, yielding ${ }^{14}$

$$
\begin{aligned}
& U^{\prime}(m) p(2-p)+2\left[U(m)-U\left(b_{2}+a_{2}\right)\right] p^{\prime}(1-p) \\
= & U^{\prime}(m) L(m)+\left[U(m)-U\left(b_{2}+a_{2}\right)\right] L^{\prime}(m),
\end{aligned}
$$

which has the same sign as

$$
\frac{m U^{\prime}(m)}{U(m)-U\left(b_{2}+a_{2}\right)}+e_{L}
$$

Hence, the unique critical value of $e_{L}$ for which the workers' welfare is maximized is given by $^{15}$

$$
e_{L}^{*}=-\frac{m U^{\prime}(m)}{U(m)-U\left(b_{2}+a_{2}\right)},
$$

and the workers' welfare increases with the minimum wage rate if $e_{L}>e_{L}^{*}$, but decreases if $e_{L}<e_{L}^{*}$. Since there is always a unit continuum of involuntarily unemployed workers who receive short-run unemployment benefits ( $p$ from the young generation and $1-p$ from the old generation), the marginal gain of utility from employment at the minimum wage rate with respect to $m$, and therefore also $e_{L}^{*}$, is independent of the short-run unemployment benefit. At the same time, the utility of every worker who is involuntarily unemployed in the second period of his life is the same, so $e_{L}^{*}$ is independent of the level of employment and equals the elasticity of the marginal gain of utility from employment at the minimum wage rate with respect to $m$. Furthermore, since the marginal gain of utility from employment at the minimum wage rate with respect to $m$ decreases with the long-run unemployment benefit,

14 We use that

$$
\frac{d p}{d m}=\frac{L^{\prime}(m)}{2[1-L(m)]^{1 / 2}} .
$$

${ }^{15}$ It is assumed that the second-order condition, which is the same expression as in footnote 11, is satisfied. 
also $e_{L}^{*}$ decreases with the long-run unemployment benefit. Regarding risk aversion, if $V$ is an increasing strictly concave transformation of $U$, then

$$
-\frac{m V^{\prime}(m)}{V(m)-V\left(b_{2}+a_{2}\right)}>-\frac{m U^{\prime}(m)}{U(m)-U\left(b_{2}+a_{2}\right)},
$$

which entails that the critical value of $e_{L}$ increases with the workers' risk aversion. Consequently, if the unemployment benefit depends on the length of unemployment and $b_{2}+a_{2} \leq$ $m<b_{1}+a_{1}$, then $e_{L}^{*}$ is independent of the short-run unemployment benefit, while the effects of the long-run unemployment benefit and the workers' risk aversion are analogous to those obtained in the static model. ${ }^{16}$

\section{Do Workers Benefit from an Increase in the Mini- mum Wage Rate?}

From the workers' point of view, the preferred minimum wage rate is such that the elasticity of labor demand equals $e_{L}^{*}$. In order to obtain an estimate of the magnitude of $e_{L}^{*}$, we consider for simplicity the static model and assume that the workers' utility function exhibits constant relative risk aversion $S \geq 0$, i.e., that $U(m)=m^{1-S} /(1-S)$ if $S \neq 1$, and $U(m)=\ln m$ if $S=1$. The average utility of involuntarily unemployed workers is then

$$
A(m)= \begin{cases}\frac{m^{2-S}-(b+\underline{a})^{2-S}}{(1-S)(2-S) N(m)} & \text { if } S \neq 1,2, \\ \frac{m \ln m-(b+\underline{a})(b+\underline{a}) \ln (b+\underline{a})}{N(m)}-1 & \text { if } S=1, \\ -\frac{\ln m-\ln (b+\underline{a})}{N(m)} & \text { if } S=2 .\end{cases}
$$

By substituting for $A(m)$ in expression (2), we obtain that the critical value of $e_{L}$ is

$$
e_{L}^{*}= \begin{cases}-\frac{(1-S)(2-S)(1-v)}{1-S+S v-2 v+v^{2-S}}+\frac{1}{1-v} & \text { if } S \neq 1,2, \\ -\frac{1-v}{1-v+v \ln v}+\frac{1}{1-v} & \text { if } S=1, \\ \frac{1-v}{1-v+\ln v}+\frac{1}{1-v} & \text { if } S=2,\end{cases}
$$

${ }^{16}$ Similarly, $d e_{L}^{*} / d a_{1}=0$ and $d e_{L}^{*} / d a_{2}=d e_{L}^{*} / d b_{2}$, and $e_{L}^{*}$ is independent of the size of each generation of workers. If $b_{2}+a_{2}=0$ and workers are risk neutral, then $e_{L}^{*}=-1$ and an increase in $m$ benefits the workers if the demand for labor is inelastic, but harms the workers if the demand for labor is inelastic. 
where $v \equiv(b+\underline{a}) / m$ is the proportion of the minimum wage rate that is covered by the unemployment benefit combined with the value of leisure and home production for the workers who have the lowest reservation wage rate.

The question that now naturally arises is what are the empirical values of $v$ and $S$ ? Concerning $v$, no direct measurement seems to exist. However, for the OECD countries, OECD (2004) tabulates the net replacement rate, i.e., the proportion of the wage rate that is replaced by unemployment benefits including means-tested social assistance, with all amounts being adjusted for the effects of payroll deductions and taxation. The net replacement rate depends on the worker's wage rate and the length of unemployment, and it differs considerably between countries. Thus, for a single wage worker without children who in 2002 was earning $67 \%$ of an average production worker's wage rate before becoming unemployed, the net replacement rate in OECD countries for short-term unemployment varies from a low of $40 \%$ to a high of $87 \%$ (Table $3.1 \mathrm{~b}$ in OECD, 2004), with an average of $66 \%{ }^{17}$ The corresponding net replacement rate in OECD countries for long-term unemployment varies from a low of $0 \%$ to a high of $82 \%$ (Table 3.2b in OECD, 2004), with an average of $52 \%$. Since the minimum wage rate is significantly smaller than $67 \%$ of an average production worker's wage rate, ${ }^{18}$ and the net replacement rate does not impute any value of leisure and home production, the value of $v$ is likely to be substantially higher than the net replacement rates.

Turning to $S$, its empirical value has been estimated by a variety of methods. Using actual consumption expenditures, Hansen and Singleton (1982) estimate that the relative risk aversion lies in the range of 0.68 to 0.97 , and Mankiw (1985) that it lies in the range of 2.44 to 5.26. Based on answers to survey questions, Barsky et al. (1997) estimate that the relative risk aversion lies in the range of 0.7 to 15.8 .

In order to ascertain how an increase in the minimum wage rate would affect workers' welfare, the actual elasticity of labor demand has to be compared with the critical value that can be computed from the empirical values of $v$ and $S$. Concerning the actual elasticity of

\footnotetext{
17 The averages in this paragraph are calculated by the author.

${ }^{18}$ For OECD contries with a minimum wage legislation, the ratio of the minimum wage rate to the average production worker's wage rate is between $32 \%$ and $62 \%$, with an average of $43 \%$ (Table A.1 in OECD, 2004).
} 
labor demand, Hamermesh (1993) surveys a large number of studies of labor demand, and he chooses -0.30 as a point estimate and $[-0.15,-0.75]$ as a reasonable confidence interval. ${ }^{19}$

In Figure 1 the upper curve shows the combinations of $S$ and $v$ at the lower bound of the confidence interval, and the lower curve shows the combinations of $S$ and $v$ at the upper bound of the confidence interval. Since $e_{L}^{*}$ decreases with $v$, combinations of $S$ and $v$ above the confidence interval are those for which a small increase in the minimum wage rate would increase the workers' welfare, while combinations of $S$ and $v$ below the confidence interval are those for which a small increase in the minimum wage rate would decrease the workers' welfare. The figure also indicates the average short-term and long-term values of $v(86 \%$ and $72 \%$, respectively), which are taken to be the average OECD net replacement rates for short- and long-term unemployed workers that were earning $67 \%$ of an average production worker's wage rate before becoming unemployed, augmented with an additional $20 \%$ for the imputed value of leisure and home production.

It is evident from Figure 1 that at the average short-term value of $v$, workers would gain from an increase in the minimum wage rate unless their risk aversion is improbably high $(S \geq 13)$. Even at the average long-term value of $v$, workers would still gain from an increase in the minimum wage rate unless they are very risk averse $(S \geq 5)$. However, given the big differences in the net replacement rates of different countries, it is also apparent that, particularly in the case of long-term unemployment, there are several countries where the net replacement rate is so low that it is questionable whether low-wage workers would benefit from an increase in the minimum wage rate. ${ }^{20}$

\section{Conclusion}

This paper has demonstrated that there exists a critical value of the elasticity of labor demand such that increases in the minimum wage rate make workers in low-paying jobs better off for higher elasticities, but worse off for lower elasticities. This critical value decreases with

\footnotetext{
19 We assume that the elasticity estimates are applicable in minimum-wage labor markets even though many of the studies consider other labor markets.

20 This includes the United States where the net replacement rate for long-term unemployed is $10 \%$. The workers' risk aversion must be less than 1.5 in order for $e_{L}^{*}$ not to exceed -0.30 .
} 
unemployment benefits and increases with workers' risk aversion. It is also shown that the average benefit level in OECD countries for short-term unemployment is so high that workers would prefer an increase in the minimum wage rate. However, in some OECD countries the benefit level for the long-term unemployed is so low that workers would probably prefer that the minimum wage rate be decreased.

The minimum wage rate has been analyzed from the point of view of the workers' welfare, and it was assumed that the level of the unemployment benefit is set independently of the minimum wage rate. Viewed from a social welfare perspective, however, both the minimum wage rate and the unemployment benefit involve a transfer of resources from the rest of the economy to workers in low-pay jobs, and a socially optimal minimum wage rate would take this into account. For a given amount of total transfer, therefore, the benefit from a higher minimum wage rate would have to be balanced against the loss from a lower unemployment benefit. As a result, the critical value of the elasticity of labor demand determined in this paper is less than the socially optimal value of the elasticity of labor demand. 


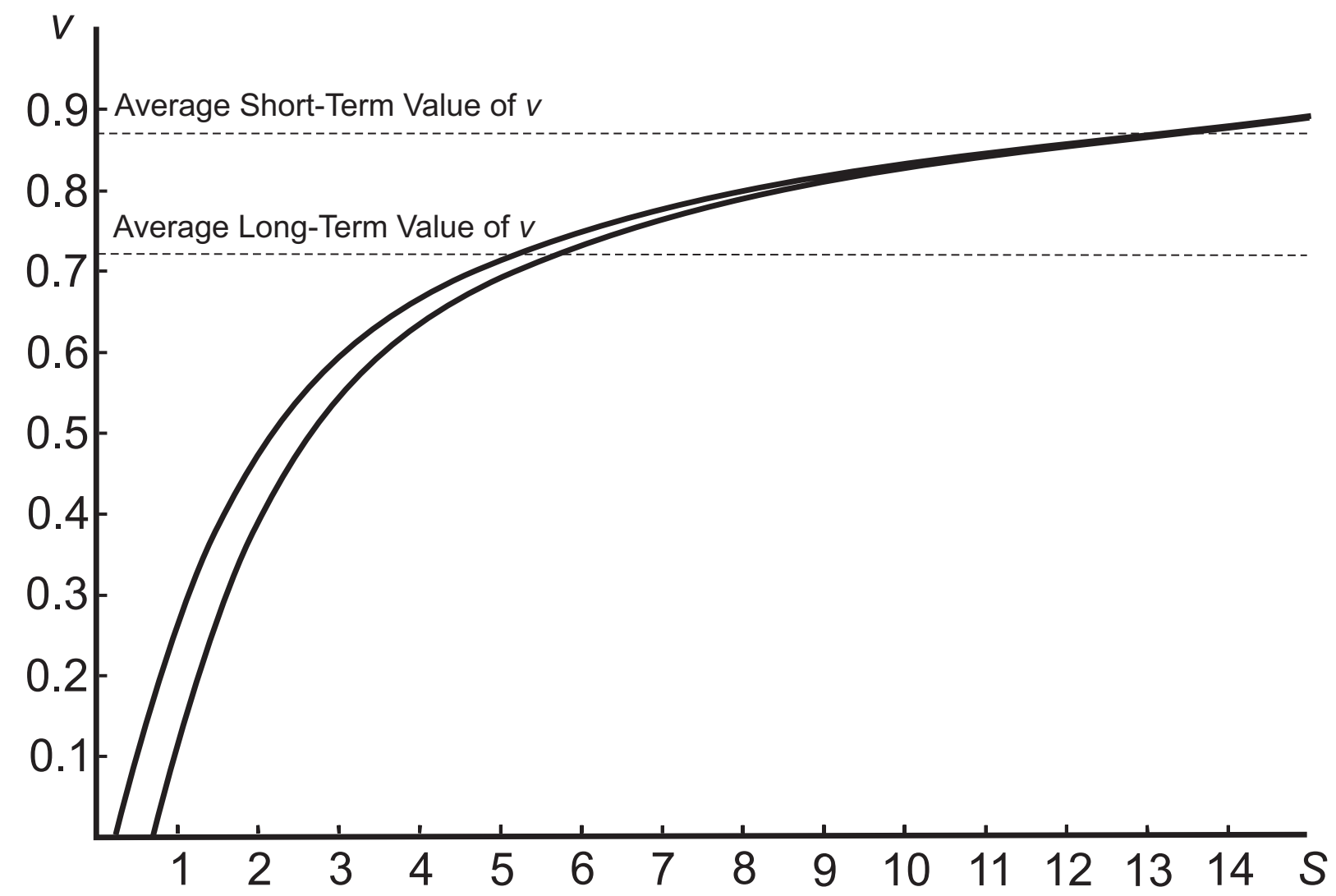

FIGURE 1: Combinations of $S$ and $v$ for which $e_{L}^{*} \in[-0.75,-0.15]$ 


\section{References}

Addison, J.T., Blackburn, M.L., 1999. Minimum wages and poverty. Industrial and Labor Relations Review 52, 393-409.

Barsky, R.B., Juster, F.T., Kimball, M.S., Shapiro, M.D., 1997. Preference parameters and behavioral heterogeneity: An experimental approach in the health and retirement study. Quarterly Journal of Economics 112, 537-579.

Burkhauser, R.V., Couch, K.A., Wittenburg, D.C., 2000. A reassessment of the new economics of the minimum wage literature with monthly data from the current population survey. Journal of Labor Economics 18, 653-680.

Card, D., Krueger, A.B., 1995. Myth and measurement: The new economics of the minimum wage. Princeton University Press.

Card, D., Krueger, A.B., 2000. Minimum wages and employment: A case study of the fastfood industry in New Jersey and Pennsylvania: Reply. American Economic Review 90, 1397-1420.

Clark, A.E., Georgellis, Y., Sanfey, P. Scarring: The Psychological impact of past unemployment. Economica 68, 221-241.

Deere, D., Murphy, K.M., Welch, F., 1995. Employment and the 1990-1991 minimum-wage hike. American Economic Review 85, Papers and Proceedings, 232-237.

Deere, D., Murphy, K.M., Welch, F., 1996. Examining the evidence on minimum wages and employment. In Kosters, M.H., ed., The effects of the minimum wage on employment. Washington, D.C.: The AEI Press, 26-54.

Dickens, R., Machin, S., Manning, A., 1999. The effects of minimum wages on employment: Theory and evidence from Britain. Journal of Labor Economics 17, 1-22.

Freeman, R.B., 1995. Comment. In Ehrenberg, R.G., ed., Review symposium on myth and measurement: The new economics of the minimum wage. Industrial and Labor Relations Review 48, 830-834.

Hamermesh, D.S., 1993. Labor demand. Princeton University Press.

Hansen, L.P., Singleton, K.J., 1983. Stochastic consumption, risk aversion, and the temporal behavior of asset returns. Journal of Political Economy 91, 249-265. 
Mankiw, N.G., 1985. Consumer durables and the real interest rate. Review of Economics and Statistics 67, 353-362.

Neumark, D., Wascher, W., 1992. Employment effects of minimum wages and subminimum wages: Panel data on state minimum wage laws. Industrial and Labor Relations Review 46, 55-81.

Neumark, D., Wascher, W., 1994. Employment effects of minimum and subminimum wages: Panel data on state minimum wage laws: Reply. Industrial and Labor Relations Review 47, 497-512.

Neumark, D., Wascher, W., 2000. Minimum wages and employment: A case study of the fast-food industry in New Jersey and Pennsylvania: Comment. American Economic Review 90, 1362-1396.

OECD, 2004. Benefits and wages: OECD indicators. OECD Publishing.

Sobel, R.S., 1999. Theory and evidence on the political economy of the minimum wage. Journal of Political Economy 107, 761-785.

Stigler, G.J., 1946. The economics of minimum wage legislation. American Economic Review 36, 358-365. 